\title{
Mutants of Escherichia coli Specifically Deficient in Respiratory Formate Dehydrogenase Activity
}

\author{
By MARIE-ANDREE MANDRAND-BERTHELOT, ${ }^{1 *}$ \\ GISÈLE COUCHOUX-LUTHAUD, ${ }^{1}$ CLAIRE-LISE SANTINI ${ }^{2}$ AND \\ GERARD GIORDANO2 \\ ${ }^{1}$ Laboratoire de Microbiologie, UM380024 du CNRS, Institut National des Sciences Appliquées \\ de Lyon, 20 avenue Albert Einstein, 69621 Villeurbanne Cedex, France \\ ${ }^{2}$ Laboratoire de Structure et Fonction des Biomembranes, UER de Luminy, \\ 70 route Léon Lachamp, 13288 Marseille Cedex 2, France
}

(Received 12 April 1988; revised 26 July 1988)

\begin{abstract}
Escherichia coli K12 mutants lacking phenazine-methosulphate-linked formate dehydrogenase (FDH-PMS) activity, but still capable of producing normal levels of benzyl-viologen-linked formate dehydrogenase (FDH-BV) and nitrate reductase activities, have been isolated following P1 localized mutagenesis. The relevant mutations mapped with the same cotransduction frequency close to the $r h a D$ gene, at $88 \mathrm{~min}$ on the $E$. coli chromosome. They were further subdivided into two classes. Class I consisted of six fdhD mutants which synthesized an inactive FDH-PMS protein with the same subunit composition as the wild-type enzyme. In contrast, class II contained four $f d h E$ mutants totally devoid of this antigen. Construction of merodiploid strains harbouring various combinations of the mutated alleles, $f d h E$ on the episome and $f d h D$ on the chromosome, led to the restoration of FDH-PMS activity by complementation of the products encoded by the respective wild-type alleles. Difference spectroscopy suggested that both $f d h D$ and $f d h E$ mutants contained normal amounts of the cytochrome $b_{559}$ associated with FDH-PMS although the cytochrome had lost its capacity for formate-dependent reduction.
\end{abstract}

\section{INTRODUCTION}

Growth of Escherichia coli anaerobically in the presence of nitrate leads to the formation of a membrane-bound multifunctional respiratory complex that catalyses the energy-conserving reduction of nitrate to nitrite by formate. This electron-transport pathway consists of formate dehydrogenase (EC 1.2.2.1) and nitrate reductase (EC 1.7.99.4) (both molybdenumcontaining iron-sulphur proteins), $b$-type cytochromes and quinone (Haddock \& Jones, 1977; Ruiz-Herrera \& DeMoss, 1969). Formate dehydrogenase has been purified to homogeneity and shown to contain three polypeptides, $\alpha\left(M_{\mathrm{r}} 110000\right), \beta\left(M_{\mathrm{r}} 32000\right)$ and $\gamma\left(M_{\mathrm{r}} 20000\right)$. Selenium is incorporated into the $110000 M_{\mathrm{r}}$ peptide and the haem is thought to be associated with the $\gamma$ subunit (Enoch \& Lester, 1975). In the absence of an exogenous electron acceptor, $E$. coli can synthesize a different formate dehydrogenase activity involved in hydrogen evolution as a component of the formate hydrogenlyase system (Peck \& Gest, 1957). Nitrate-reductase-linked formate dehydrogenase (FDH-PMS) preferentially reduces phenazine methosulphate but not benzyl viologen, while hydrogenase-linked formate dehydrogenase (FDH-BV) has the opposite specificity (Lester \& DeMoss, 1971). The distinction and cellular location of the two activities have been clearly resolved on the basis of the complete separation of two different seleniumcontaining peptides (Cox et al., 1981) with no immunological relationship (Giondano et al., 1983).

\footnotetext{
Abbreoiations: FDH-PMS, phenazine-methosulphate-linked formate dehydrogenase; FDH-BV, benzylviologen-linked formate dehydrogenase.
} 
A large variety of mutants have been isolated in $E$. coli with defects in their ability to reduce nitrate. Most of them have been selected for by their resistance to chlorate under anaerobiosis: they are pleiotropic mutants, since they have lost the activities of the three molybdoenzymes FDH-PMS, FDH-BV and nitrate reductase (Glaser \& DeMoss, 1972; Stewart \& MacGregor, 1982). Mutants specifically deficient in the two formate dehydrogenase activities have also been described, both in $E$. coli (Graham et al., 1980; Haddock \& Mandrand-Berthelot, 1982) and Salmonella typhimurium (Chippaux et al., 1977; Barrett et al., 1979). More recently, Barrett and others (Barrett et al., 1979; Barrett \& Riggs, 1982) have reported the characterization of new classes of $f d n$ mutants in $S$. typhimurium specifically defective in FDH-PMS activity.

We have identified two distinct phenotypic classes of mutants in $E$. coli which lack only FDHPMS activity and have lesions in a region equivalent to that of $S$. typhimurium. However, their biochemical, immunological and genetic properties suggest that they do not correspond to the mutant classes previously described (Barrett \& Riggs, 1982).

\section{METHODS}

Bacterial strains. The $E$. coli $\mathrm{K} 12$ strains used in this study are listed in Table 1. Merodiploid strains carrying a derivative of episome F14 were constructed as follows. F14 was transferred into strains FD171 (fdhDI), FD191 (fdhD3), FD161 (fdhEl) and FD221 (fdhE4), selecting for the presence of the $i l^{+}$and arg ${ }^{+}$markers. Recombination between chromosome and episome, occurring at a frequency of $0.1 \%$ (Miller, 1972), resulted in the integration of the $f d h D$ or $f d h E$ alleles on the episome. This event was scored by examination of the colonies on MacConkey-nitrate plates under anaerobiosis (Barrett et al., 1979): very rare red colonies of small size exhibiting an FDH-PMS- phenotype (homogenotes $f d h D / f d h D$ or $f d h E / f d h E$ ) were clearly distinguished from the bulk of large pale pink colonies of the wild-type (heterogenotes $f d h D^{+} / f d h D$ or $f d h E^{+} / f d h E$ ). The former were purified and checked. The mutated episome was then transferred to recA Tet $^{R}$ derivatives of strains FD171, FD191, FD161 and FD221 selecting for $i v^{+} \arg ^{+}$Tet $^{\mathrm{R}}$.

Media, growth conditions and genetic techniques. The strains were grown in L-broth medium supplemented with glucose $(0.2 \%, w / v)$, sodium selenite $(2 \mu \mathrm{M})$ and ammonium molybdate $(2 \mu \mathrm{M})$ (Wu \& Mandrand-Berthelot, 1986). When indicated, potassium nitrate $(1 \%, w / v)$ was added. For enzyme assays, anaerobic growth was accomplished at $37^{\circ} \mathrm{C}$ in non-agitated closed vessels filled almost to the top. For ${ }^{35} \mathrm{~S}$-labelling experiments, Casamino acids were omitted from the basal medium used and the ammonium sulphate was replaced with $\mathrm{NH}_{4} \mathrm{Cl}$ (Giordano et al., 1983). Minimal medium was M63 (Miller, 1972) supplemented with thiamin $\left(0.5 \mu \mathrm{g} \mathrm{ml}^{-1}\right)$. When required, $\mathrm{L}-$ amino acids $\left(100 \mu \mathrm{g} \mathrm{ml}^{-1}\right)$ and tetracycline hydrochloride $\left(10 \mu \mathrm{g} \mathrm{ml}^{-1}\right)$ were added.

Interrupted mating experiments, transductions with phage P1kc and episome transfers were performed according to Miller (1972).

Isolation and identification of the FDH-PMS- mutants. A P1kc lysate was prepared on strain HfrH and concentrated to $5 \times 10^{11}$ phage $\mathrm{ml}^{-1}$ by centrifugation. It was then mutagenized with $0.4 \mathrm{M}$-hydroxylamine hydrochloride for $7 \mathrm{~h}$ at $37^{\circ} \mathrm{C}$, according to the procedure described by Murgola \& Yanofsky (1974). Once sedimented by centrifugation, the surviving phage ( $2 \%$ of the original stock) were resuspended in $\mathrm{L}$-broth medium supplemented with $5 \mathrm{mu}-\mathrm{CaCl}_{2}$. The mutated lysate was used to transduce strain D54 ( $\mathrm{raD}$ met $B$ ), selecting for rha $D^{+}$colonies which had coinherited the FDH-PMS- phenotype, identified by means of the soft agar dye overlay methods described previously (Wu \& Mandrand-Berthelot, 1986).

Preparation of extracts and enzyme assays. Cultures were harvested at the mid- to late-exponential phase of growth and suspended, after being washed twice, in a buffer containing $25 \mathrm{mM}-\mathrm{KH}_{2} \mathrm{PO}_{4} / 25 \mathrm{mM}-\mathrm{Na}_{2} \mathrm{HPO}_{4}(\mathrm{pH}$ 6.8) and 1 mu-benzamidine hydrochloride, to a final concentration close to $10 \mathrm{mg}^{\mathrm{p}}$ potein $\mathrm{ml}^{-1}$. Bacteria were ruptured in a French pressure cell at 10000 p.s.i. (69 MPa). Cellular debris was removed by centrifugation at 12000 $\boldsymbol{g}$ for $15 \mathrm{~min}$ and the supernatant containing the crude extract was used directly for enzyme assays. FDH-PMS, FDH-BV, nitrate reductase and hydrogenase activities were measured spectrophotometrically at $600 \mathrm{~nm}$ and at $30^{\circ} \mathrm{C}$ as described previously (Wu \& Mandrand-Berthelot, 1986). Measurements on whole cells were performed in the same way.

Gas production was estimated in Durham tubes filled with rich medium supplemented with glucose $(0.8 \%$, $\mathrm{w} / \mathrm{v})$, sodium selenite $(2 \mu \mathrm{M})$ and ammonium molybdate $(2 \mu \mathrm{M})$. Formate hydrogenlyase activity was followed manometrically by measuring formate-dependent evolution of hydrogen according to the procedure of Azoulay \& Marty (1970). Protein was measured by the Lowry method, using bovine serum albumin (fraction V, NBC) as standard.

Immunological analysis. Rocket immunoelectrophoresis was performed on crude extracts solubilized with (1\%, w/v) Triton X-100 as described by Graham et al. (1980), using an antiserum specific for the FDH-PMS enzyme purified essentially following the method of Enoch \& Lester (1975). 
Table 1. Strains of E. coli K12

Strain

HfrH
D54
EMG29
mal38
CGSC4443†

GY05

FD17

FD18

FD19

FD24

FD25

FD16

FD20

FD21

FD22

$161 R$

F14

FD171

FD191

FD161

FD221

F14-1/FD171rec

F14-2/FD191rec

F14-3/FD161rec

F14-4/FD221rec
Genetype

Hfr

$\mathrm{F}^{+}$metBI rhaDS4

$\mathrm{F}^{-}$metB his trpB lac rpsL

$\mathrm{F}^{-}$proB his trpB lac rpsL

$F^{-}$thi thr leu arg $H$ his pro pur $E$ chlB lac $Y$

mtl xyl malA ara gal rpsL tond

F $^{-}$as EMG29 also fdhD6

$\mathrm{F}^{+}$fdhD1 metBI

$\mathrm{F}^{+} f d h \mathrm{D} 2$ met $B 1$

$\mathrm{F}^{+} f d h D 3$ metBI

$\mathrm{F}^{+}$fdhD4 metBI

$\mathrm{F}^{+} f d h D S$

$\mathrm{F}^{+}$fdhEl

$\mathrm{F}^{+}$fdhE2 metB/This work

$\mathrm{F}^{+}$fdhE3

$\mathrm{F}^{+}$fdhE4 metBl

F-hisG1 ilvDl6 glpK1 argHl thi-I lac YI

or Z4 or $20 \mathrm{gal}-6 \mathrm{malAl} \mathrm{mtl}-2$ rpsLs.

9 or 17 tonA 2 or 22 tsx-7 $\lambda^{2} \lambda^{-} \sup E 44$ rhaD54

$\mathrm{F}^{\prime} \mathrm{F} 14$ ilvD+ argEH H $^{+} / \mathrm{ilv}-8$ pro-2 his-4 lacYl galK rpsL

$\mathrm{F}^{-}$as $161 \mathrm{R}$, but rhaD+ metBl fdhDl

$\mathrm{F}^{-}$as $161 \mathrm{R}$, but rha $D^{+} f d h D 3$

as $161 \mathrm{R}$, but rhaD $D^{+}$fdhEl

$F^{\prime}$ s 161R, but rhaD' fdhEA

$\mathrm{F}^{\prime}$ F14 fdhD1/FD171 srlC300: :Tn10 recA56

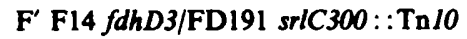
recA56

$F^{\prime}$ F14 fdhE1/FD161 srlC300::Tn10 recA56

$F^{\prime}$ F14 fdhE4/FD221 srlC300::Tn10 recA56
Source or reference

Low (1972)

Power (1967)

NCIB*

T. Silhavy

F. Casse

Mandrand-Berthelot et al. (1978)

This work

This work

This work

This work

This work

This work

This work

This work

rhaD met $B^{+}$derivative of $\mathrm{LIN} 161$, by transduction with $\mathrm{P} 1$

F. Jacob (Pasteur Institute)

P1(FD17) $\times 161 \mathrm{R} \mathrm{rha}^{+}$selection P1(FD19) $\times 161 R r^{+} a^{+}$selection P1(FD16) $\times 161 \mathrm{R}$ rhat selection PI(FD22) $\times 161 \mathrm{R}$ rha $^{+}$selection

This work

This work

This work

This work

*NCIB, National Collection of Industrial Bacteria, Aberdeen, UK.

+ CGSC, Coli Genetic Stock Center, Yale University, via B. Bachmann.

For the analysis of the subunit composition of FDH-PMS, crude extracts of cells labelled with $\mathrm{K}_{2}{ }^{35} \mathrm{SO}_{4}$ were centrifuged at $170000_{8}$ for $90 \mathrm{~min}$ to separate them into a soluble and a membrane fraction. The membrane fraction containing the FDH-PMS activity was immunoprecipitated by the addition of $30 \mu \mathrm{l}$ antiserum per $\mathrm{mg}$ membrane protein solubilized with Triton X-100. Antigenic material was analysed by determining the distribution of radioactivity in polyacrylamide gels $(10 \%, \mathrm{w} / \mathrm{v})$ in the presence of SDS as described previously (Giordano et al., 1978).

Cytochrome scans. Absorption spectra of the frozen-thawed cell preparations were recorded at room temperature in a double-beam spectrophotometer whose specifications have been reported by Denis \& Richaud (1982). Samples were introduced into one cuvette and they were first oxidized by potassium ferricyanide, then sequentially reduced by addition of ascorbate, formate and dithionite.

\section{RESULTS}

\section{Characterization of a mutant devoid of FDH-PMS activity}

Mutant GY05 had been previously isolated following $N$-methyl- $N$ '-nitro- $N$-nitrosoguanidine treatment of strain EMG29 and detected by its absence of colour using the formate-benzyl viologen dye overlay procedure (Mandrand-Berthelot et al., 1978). It lacked FDH-PMS activity but retained the nitrate reductase molybdoenzyme. Surprisingly, it exhibited normal levels of FDH-BV activity after cell breakage (Table 2). These biochemical properties led us to 
Table 2. Enzyme activities in FDH-PMS- mutants grown under anaerobiosis in the presence or absence of nitrate

Bacteria were grown anaerobically in L-broth medium as described in Methods. The activities of FDHPMS and FDH-BV are expressed as $\mu \mathrm{mol}$ formate $\min ^{-1}$ (mg protein) $)^{-1}$; the results are mean values from two or three independent experiments. ' 0 ' indicates values smaller than 0.001 .

\begin{tabular}{|c|c|c|c|c|c|}
\hline \multirow[b]{2}{*}{ Strain } & \multirow[b]{2}{*}{$f d h$ genotype } & \multicolumn{2}{|c|}{ FDH-PMS } & \multicolumn{2}{|c|}{ FDH-BV } \\
\hline & & $-\mathrm{NO}_{\overline{3}}^{-}$ & $+\mathrm{NO}_{3}^{-}$ & $-\mathrm{NO}_{\overline{3}}^{-}$ & $+\mathrm{NO}_{3}^{-}$ \\
\hline $\begin{array}{l}\text { D54 } \\
\text { FD17 } \\
\text { FD18 } \\
\text { FD19 } \\
\text { FD24 } \\
\text { FD25 }\end{array}$ & $\begin{array}{l}\text { Wild-type } \\
\text { fdhD } \\
\text { fdhD } \\
\text { fdhD } \\
\text { fdhD } \\
\text { fdhD }\end{array}$ & $\begin{array}{l}0.04 \\
0 \\
0 \\
0 \\
0 \\
0\end{array}$ & $\begin{array}{l}0.89 \\
0.005 \\
0.004 \\
0 \\
0 \\
0.02\end{array}$ & $\begin{array}{l}0.24 \\
0.13 \\
0.05 \\
0.09 \\
0.2 \\
0.21\end{array}$ & $\begin{array}{l}0 \\
0 \\
0 \\
0 \\
0 \\
0\end{array}$ \\
\hline $\begin{array}{l}\text { FD16 } \\
\text { FD20 } \\
\text { FD21 } \\
\text { FD22 }\end{array}$ & $\begin{array}{l}f d h E \\
f d h E \\
f d h E \\
\text { fdhE }\end{array}$ & $\begin{array}{l}0 \\
0 \\
0 \\
0\end{array}$ & $\begin{array}{l}0 \\
0.002 \\
0 \\
0\end{array}$ & $\begin{array}{l}0.16 \\
0.17 \\
0.24 \\
0.13\end{array}$ & $\begin{array}{l}0 \\
0 \\
0 \\
0\end{array}$ \\
\hline $\begin{array}{l}\text { EMG29 } \\
\text { GY05 }\end{array}$ & $\begin{array}{l}\text { Wild-type } \\
\text { fdhD }\end{array}$ & $\begin{array}{l}0.018 \\
0\end{array}$ & $\begin{array}{l}0.45 \\
0.001\end{array}$ & $\begin{array}{l}0.30 \\
0.42\end{array}$ & $\begin{array}{l}0.001 \\
0\end{array}$ \\
\hline
\end{tabular}

Table 3. Pl-mediated transduction mapping of fahD and chlB mutations

The $f d h D$ allele was scored using the dye overlay procedures for FDH-BV and FDH-PMS activities (Mandrand-Berthelot et al., 1978; Wu \& Mandrand-Berthelot, 1986). The chlB allele was scored using the dye overlay methods for FDH-BV and nitrate reductase activities (Wu \& Mandrand-Berthelot, 1986).

\begin{tabular}{|c|c|c|c|c|c|}
\hline $\begin{array}{l}\text { Donor } \\
\text { strain }\end{array}$ & $\begin{array}{l}\text { Recipient } \\
\text { strain }\end{array}$ & $\begin{array}{l}\text { Selected } \\
\text { marker }\end{array}$ & $\begin{array}{l}\text { Colonies } \\
\text { scored }\end{array}$ & \multicolumn{2}{|c|}{$\begin{array}{l}\text { Percentage } \\
\text { cotransduction }\end{array}$} \\
\hline GY0S $(f d h D)$ & mal38 (metE ilv) & $\begin{array}{l}i l v^{+} \\
\text {metE }\end{array}$ & $\begin{array}{l}143 \\
149\end{array}$ & $\begin{array}{l}0 \text { fdhD } \\
1 \text { fdhD }\end{array}$ & $\begin{array}{l}8 \text { met E }^{+} \\
44 \mathrm{ilv}^{+}\end{array}$ \\
\hline GY05 & D54 (rhaD met B) & $\begin{array}{l}\text { rhad }{ }^{+} \\
\text {met } B^{+}\end{array}$ & $\begin{array}{l}241 \\
296\end{array}$ & $\begin{array}{r}68 f d h D \\
8 f d h D\end{array}$ & $\begin{array}{l}22 \text { met } B^{+} \\
10 \text { rha } D^{+}\end{array}$ \\
\hline CGSC4443 (chlB) & $\mathrm{mal} 38$ & $\begin{array}{l}i l v^{+} \\
\text {met } E^{+}\end{array}$ & $\begin{array}{l}145 \\
149\end{array}$ & $\begin{array}{r}0 \mathrm{chlB} \\
14 \mathrm{chlB}\end{array}$ & $\begin{array}{l}3 \text { met } E^{+} \\
40 i v^{+}\end{array}$ \\
\hline CGSC 4443 & D54 & $\begin{array}{l}\text { rhad } D^{+} \\
\text {metB }\end{array}$ & $\begin{array}{l}132 \\
148\end{array}$ & $\begin{array}{l}6 \mathrm{chlB} \\
1 \mathrm{chlB}\end{array}$ & $\begin{array}{l}12 \text { met }^{+} \\
10 \text { rhaD }^{+}\end{array}$ \\
\hline
\end{tabular}

distinguish it from other mutants of $E$. coli that we isolated previously and which had lost both formate dehydrogenase activities simultaneously ( $f d h A, B$ and $C$ : Mandrand-Berthelot $e t$ al., 1978; Haddock \& Mandrand-Berthelot, 1982). We thus decided to determine the map location of the relevant locus, designated $f d h D$. Mutant GY05 was used as a recipient strain in uninterrupted mating experiments with $\mathrm{HfrH}$ : among the pro+, $\mathrm{lac}^{+}, \mathrm{trp}^{+}$or his $\mathrm{s}^{+}$selected recombinants, none had inherited the $f d h D$ allele. Mutant GY05 was then tested for P1mediated cotransduction of the fdhD mutation with known genetic markers located in the opposite position on the circular map. No cotransduction was found with $x y l, m t l, p y r E$ or $i l v$, but a low linkage was observed with met $E$ (Table 3 ). Coinheritance of adjacent markers $r h a D$ and $m e t B$ was subsequently tested to locate $f d h D$ more accurately. In this area of the bacterial chromosome lies the chlB gene, whose mutations lead to impairment in the synthesis of both formate dehydrogenases and nitrate reductase (Haddock \& Jones, 1977). To rule out the possibility that the $f d h D$ mutation was a particular allelic form of the chlB gene, we compared the cotransduction frequency of the $c h l B$ mutation carried by strain CGSC 4443 with the same selected markers (Table 3). Our data clearly show that fdhD and chlB lesions belong to two separate loci which are distant from each other. Additional evidence was obtained by the direct 
Table 4. Pl-mediated transduction mapping of $f d h D$ and fdhE mutations

Strain $161 \mathrm{R}$ (rhaDS4 glpK arg $H$ ) was used as recipient for transductions, except with P1(FD21), where strain D54 (rhaD54 metB) was used.

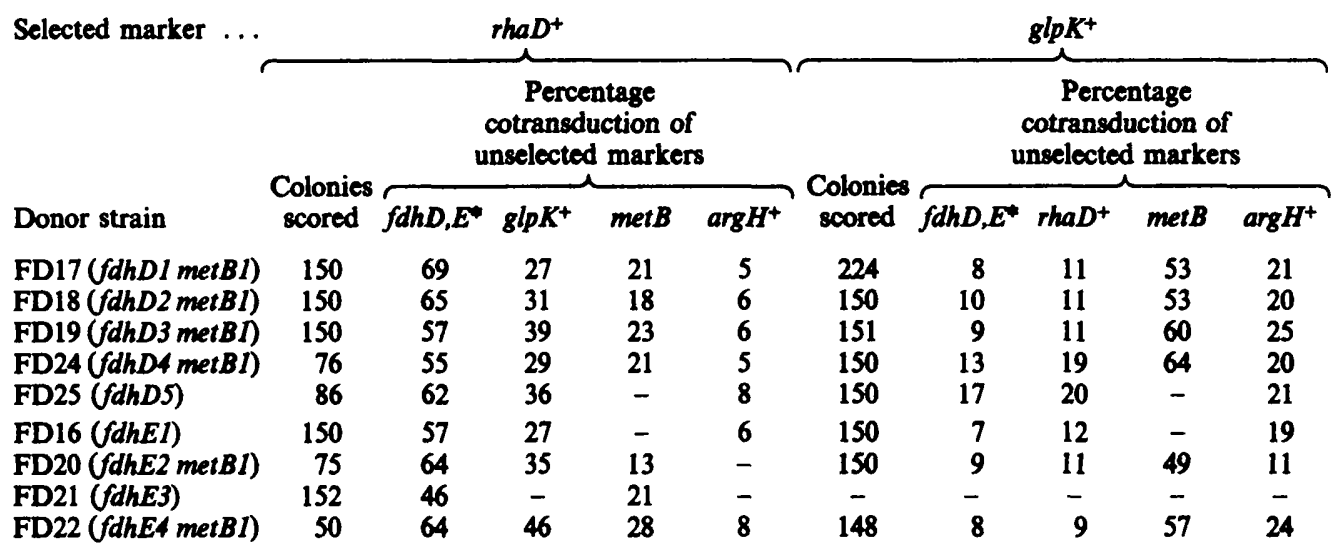

- $f d h D$ and $f d h E$ markers were scored using the dye overlay procedures for FDH-BV and FDH-PMS activities (Wu \& Mandrand-Berthelot, 1986).

selection of $c h l B^{+}$transductants in a cross between strain GY05 (fdhD) as donor and strain CGSC4443 (chlB) as recipient (data not shown): only $8 \%$ of the ChlB ${ }^{+}$clones had inherited the donor FDH-PMS-, FDH-BV-phenotype, suggesting that the chlB and $f d h D$ alleles are at least one minute apart on the $E$. coli genome.

\section{Isolation and preliminary study of additional mutants lacking FDH-PMS activity}

In the light of the close proximity of the $f d h D$ and rhaD loci (see Table 3), we sought other similar mutants, using a P1 localized mutagenesis procedure to transduce strain D54 (rhaD) and select $\mathrm{Rha}^{+}$recombinants (see Methods). A total of 2300 transductants were screened for their ability to reduce PMS with formate by the dye overlay test. FDH-PMS- potential candidates were purified and scored for the presence of both formate dehydrogenases and nitrate reductase using dye indicator media (Wu \& Mandrand-Berthelot, 1986). Nine independent FDH-PMSmutants were thus identified. They could be further separated into two classes. Like mutant GY05, the five mutants of class I, FD17, FD18, FD19, FD24 and FD25, additionally lacked the ability to reduce BV with formate (as detected on Petri dishes), while the four other mutants, FD16, FD20, FD21 and FD22, belonging to class II, remained unaffected. In addition, formate hydrogenlyase activity (consisting of FDH-BV and hydrogenase activities) was estimated in Durham tubes by gas production from glucose in rich medium. Our results indicate that it was considerably diminished (to about $25 \%$ of the level found in the wild-type strain) only in the $f d h D$ mutants of class I. The mutants of class II showed the same activity as the wild-type. This latter class was further designated $f d h E$.

To confirm the map location of the mutants, each $f d h D$ or $f d h E$ mutant was used as donor in P1-mediated transduction with strain 161R (rhaD glpK argH), except FD21 which was crossed with strain D54 (rhaD metB). Our data showed an average linkage of $60 \%$ with rhaD, in agreement with that previously reported for GY05 (Table 3), and $10 \%$ with glpK (Table 4). Three-factor cross analysis of the $g l p K^{+}$transductants gave the following order: $f d h(D E)$-rhaD$g l p K$ at $88 \mathrm{~min}$ on the $E$. coli chromosome. A $16 \%$ cotransduction frequency was also observed with the $g \ln A$ marker at $87 \mathrm{~min}$ (data not shown). Thus $f d h D$ and $f d h E$ behave as closely-linked genes lying midway between $g \ln A$ and $g l p K$.

\section{Biochemical characteristics of the mutants}

The levels of the two formate dehydrogenase activities were determined in crude extracts of each FDH-PMS- mutant, after anaerobic growth on rich medium in the presence or absence of 
Table 5. Formate dehydrogenase activities of the merodiploid fdhE/fdhD strains

Bacteria were grown anaerobically in L-broth medium as described in Methods. The activities of FDHPMS and FDH-BV are expressed as $\mu$ mol formate $\min ^{-1}\left(\mathrm{mg}\right.$ protein) ${ }^{-1}$; the results are mean values from triplicate experiments.

\begin{tabular}{|c|c|c|c|c|c|}
\hline \multirow[b]{2}{*}{ Strain } & \multirow{2}{*}{$\begin{array}{c}\text { Merodiploid } \\
\text { episome/chromosome }\end{array}$} & \multicolumn{2}{|c|}{ FDH-PMS } & \multicolumn{2}{|c|}{ FDH-BV } \\
\hline & & $-\mathrm{NO}_{3}^{-}$ & $+\mathrm{NO}_{3}^{-}$ & $-\mathrm{NO}_{3}^{-}$ & $+\mathrm{NO}_{3}^{-}$ \\
\hline $\begin{array}{l}\text { F14-1/FD171 rec } \\
\text { F14-2/FD191 rec } \\
\text { F14-3/FD161 rec } \\
\text { F14-4/FD221 rec }\end{array}$ & $\begin{array}{l}\text { fdhD1/fdhDI } \\
\text { fdhD3/fdhD3 } \\
\text { fdhEl/fdhEl } \\
\text { fdhE4/fdhE4 }\end{array}$ & $\begin{array}{l}0.001 \\
0.002 \\
0 \\
0\end{array}$ & $\begin{array}{l}0.001 \\
0.003 \\
0.001 \\
0\end{array}$ & $\begin{array}{l}0.02 \\
0.014 \\
0.046 \\
0.05\end{array}$ & $\begin{array}{l}0 \\
0 \\
0 \\
0\end{array}$ \\
\hline $\begin{array}{l}\text { F14-3/FD171 rec } \\
\text { F14-3/FD191 rec } \\
\text { F14-3/FD221 rec }\end{array}$ & $\begin{array}{l}\text { fdhEl/fdhDl } \\
\text { fdhEl/fdhD3 } \\
\text { fdhEl/fdhE4 }\end{array}$ & $\begin{array}{l}0.037 \\
0.075 \\
0\end{array}$ & $\begin{array}{l}0.37 \\
0 \cdot 38 \\
0.001\end{array}$ & $\begin{array}{l}0.028 \\
0.029 \\
0.04\end{array}$ & $\begin{array}{l}0 \\
0 \\
0\end{array}$ \\
\hline $\begin{array}{l}\text { F14-4/FD171 rec } \\
\text { F14-4/FD191 rec } \\
\text { F14-4/FD161 rec }\end{array}$ & $\begin{array}{l}\text { fdhE4/fdhDI } \\
\text { fdhE4/fdhD3 } \\
f d h E 4 \mid f d h E l\end{array}$ & $\begin{array}{l}0.038 \\
0 \cdot 102 \\
0\end{array}$ & $\begin{array}{l}0 \cdot 28 \\
0 \cdot 40 \\
0\end{array}$ & $\begin{array}{l}0.01 \\
0.023 \\
0.035\end{array}$ & $\begin{array}{l}0 \\
0 \\
0\end{array}$ \\
\hline $161 R$ & Wild-type & 0.068 & 0.50 & 0.066 & 0 \\
\hline
\end{tabular}

nitrate. Activities of nitrate reductase (a component of the formate nitrate reductase complex) and of hydrogenase (a component of the formate hydrogenlyase system) were simultaneously assayed. As previously outlined for mutant GY05, all the $f d h D$ and $f d h E$ mutants were totally devoid of FDH-PMS activity but they displayed nearly wild-type specific activities of FDH-BV, except FD18 and FD19, which showed a three- to fivefold reduction in the level of this enzyme. On the other hand, nitrate reductase and hydrogenase activities were comparable to those found in the wild-type strain (data not shown). Growth of cells under anaerobic conditions with or without nitrate allowed us to check that formation of enzymes in the mutants followed a pattern identical to that known for the wild type: FDH-BV and hydrogenase were synthesized in the absence of nitrate and completely repressed in its presence (Table 2 and data not shown); nitrate reductase was induced about tenfold by nitrate (not shown).

In order to find the reason for the difference in the phenotypic behaviour of $f d h D$ and fdhE classes relative to the in situ BV dye overlay test on Petri dishes, we compared FDH-BV, nitrate reductase and hydrogenase activities in intact whole cells and in crude extracts after cell breakage by a French press. We were surprised to detect no differences in any of the mutants tested. In particular, FDH-BV activity of $f d h D$ mutants was the same in whole cells and crude extracts and it was comparable to that measured in the wild-type and fdhE mutants (data not shown). In addition, formate hydrogenlyase activity assayed manometrically by the Warburg procedure gave identical results with whole cells of mutants FD17 $(f d h D)$ and FD16 $(f d h E)$ (data not shown), although, as reported above, gas production in Durham tubes was strongly decreased in all $f d h D$ mutants. The reason for this discrepancy is unknown, but it was of considerable help to discriminate between the two groups of mutants.

\section{Analysis of fdhD/fdhE merodiploid strains}

In order to assess further the existence of two distinct fdhD and fdhE genes, we constructed a series of merodiploid strains harbouring various combinations of the $f d h D 1, f d h D 3, f d h E 1$ and fdhE4 alleles originating from strains FD17, FD19, FD16 and FD22 respectively (see Methods and Table 1). Both formate dehydrogenase activities were then assayed in every merodiploid strain after anaerobic growth on rich medium in the presence or absence of nitrate (Table 5). As expected, crude extracts of reference merodiploids bearing the same type of mutation on the episome as well as on the chromosome (i.e. $f d h D x / f d h D y$ or $f d h E x / f d h E y$ ) failed to produce FDH-PMS activity, like the original haploid mutants. In contrast, in merodiploids carrying any combination between an $f d h E$ allele on the episome and an $f d h D$ allele on the chromosome (i.e. $f d h E x(f d h D y)$, FDH-PMS activity was restored to a level similar to that found in the parental 

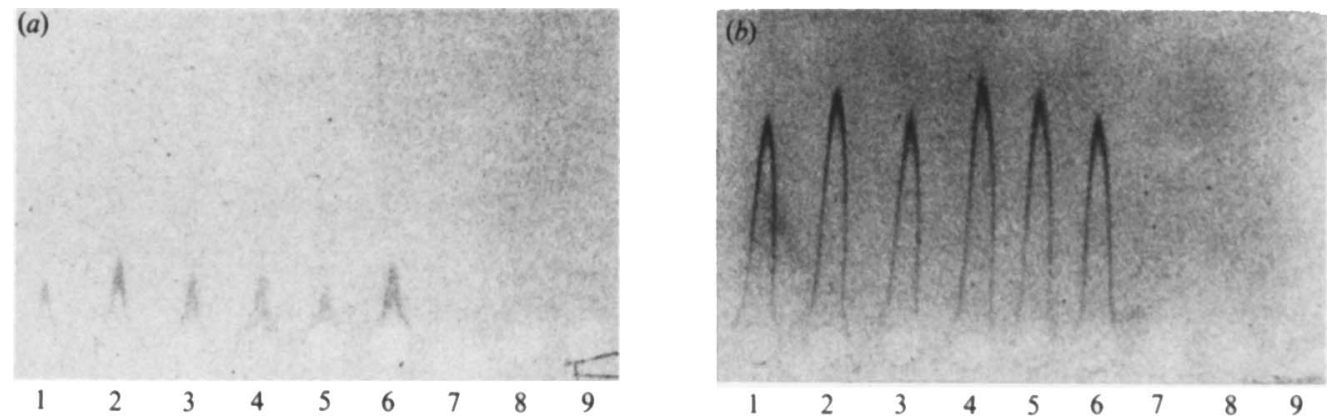

Fig. 1. Analysis by rocket immunoelectrophoresis of FDH-PMS protein in fdhD and fdhE mutants. Crude extracts ( $8 \mathrm{mg}$ protein $\mathrm{ml}^{-1}$ ) were obtained from cells grown anaerobically without nitrate $(a)$ or with nitrate (b). Each well received $7.5 \mu l$ crude extract solubilized with Triton X-100. Plates were poured with $3.3 \mathrm{ml} 1 \%$ agarose containing (a) $15 \mu \mathrm{l}$ or (b) $30 \mu \mathrm{l}$ anti-FDH-PMS serum. 1, Wild-type strain EMG29; 2, fdhD mutant GY05; 3, wild-type strain D54; 4, fdhD mutant FD17; 5, fdhD mutant FD19; 6, fdhD mutant FD24; 7, fdhE mutant FD16; 8, fdhE mutant FD21; 9, fdhE mutant FD22.

strain $161 \mathrm{R}$. The reason for the decrease in FDH-PMS activity is likely to be that loss of the $\mathrm{F}^{\prime}$ factor can reach $50 \%$ in some cultures. In all cases, the FDH-BV activity in the merodiploid strains varied from 10 to $25 \%$ of the values obtained with the primary mutants (compare Table 5 with Table 2). This could result from the transfer of the various $f d h D$ and $f d h E$ alleles in the multiply-marked strain $161 \mathrm{R}$, which served as recipient for the construction of all merodiploids and also shows decreased FDH-BV activity (Table 5).

These results demonstrate that pairs of $f d h D$ and $f d h E$ mutations are able to complement with each other to restore a wild-type phenotype of FDH-PMS activity. Thus they belong to two different closely-linked genes.

\section{FDH-PMS protein synthesis in FDH-PMS mutants}

To determine whether the $f d h D$ and $f d h E$ mutants produce an FDH-PMS protein identical to that of the wild-type, we analysed them immunochemically, employing antiserum which had been raised to the purified FDH-PMS enzyme.

Crude extracts of mutant and parental strains, solubilized with Triton X-100, were submitted to 'rocket' immunoelectrophoretic analysis (Giordano et al., 1983) (Fig. 1). Although they have lost FDH-PMS activity, $f d h D$ mutants (GY05, FD17, FD19 and FD24) still synthesize amounts of FDH-PMS protein comparable to either of the wild-type proteins in strains EMG29 and D54. In contrast, $f d h E$ mutants (FD16, FD21 and FD22) did not make any FDH-PMS antigen, whatever the growth conditions. This additional biochemical difference gives further support to the distinction of two groups in the FDH-PMS- mutants.

The distribution of immunoprecipitable FDH-PMS protein after cell fractionation was similar for the $f d h D$ mutants and the wild-type strain $(75 \%$ in the membrane fraction and $25 \%$ in the soluble fraction). This ruled out the possibility that the mutation affecting $f d h D$ resulted in the accumulation of a soluble (inactive) form of FDH-PMS enzyme.

To characterize the structure of the FDH-PMS protein produced in the $f d h D$ mutants, we compared its subunit composition with that of the protein from the parental strain. Membrane fractions labelled after growth of cells in the presence of $\mathrm{K}_{2}{ }^{35} \mathrm{SO}_{4}$ were prepared from the representative mutant FD17 and the wild-type strain D54. Immunoprecipitated material obtained following incubation with antiserum raised to purified FDH-PMS enzyme was analysed by SDS-PAGE (Fig. 2). In both cases, the antigen recovered had a polypeptide content characteristic of the FDH-PMS enzyme, with equimolar amounts of $\alpha$ subunit $\left(M_{\mathrm{r}} 110000\right)$ and $\beta$ subunit $\left(M_{\mathrm{r}} 32000\right)(1 \alpha: 1 \beta$ for D54; $0.95 \alpha: 1 \beta$ for FD17). Except for the $\gamma$ subunit, which we were not able to identify in this experiment as previously described (Giordano et al., 1980), we can conclude that the molecular composition of FDH-PMS protein remains unchanged in the fdhD mutants. 


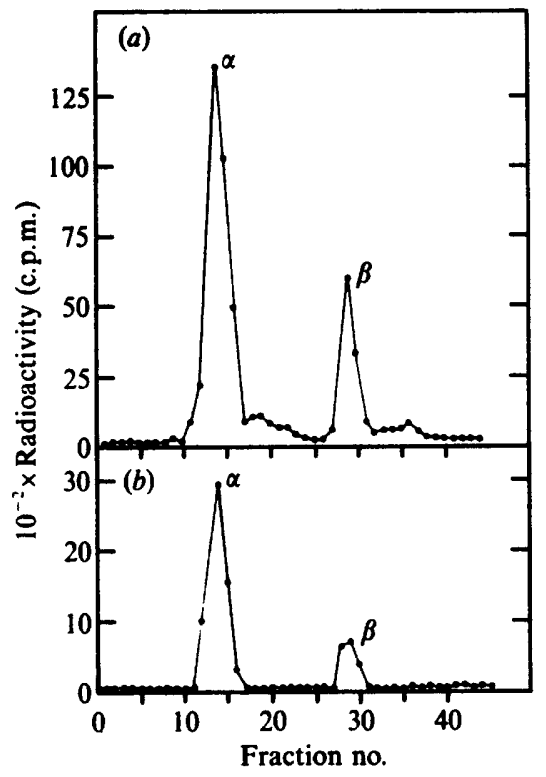

Fig. 2. Subunit composition of membrane-bound FDH-PMS in wild-type strain D54 and in mutant strain FD17 $(f d h D)$. Cells were grown anaerobically in the presence of nitrate. Triton X-100 solubilized membrane fractions, labelled with $\mathrm{K}_{2}{ }^{35} \mathrm{SO}_{4}$, of $(a)$ strain D54 [ $2 \times 10^{7}$ c.p.m. (mg protein) $\left.{ }^{-1}\right]$ and $(b)$ strain FD17 $0.8 \times 10^{-6}$ c.p.m. (mg protein) $\left.{ }^{-1}\right]$ were incubated with anti-FDH-PMS serum as described in Methods. The immunoprecipitates were subjected to electrophoresis in SDS/10\% polyacrylamide gels. The distribution of radioactivity was determined by scintillation counting of $1 \mathrm{~mm}$ slices of gels.

\section{Spectral analysis of b-type cytochromes}

The components of the formate-nitrate reductase pathway, formate dehydrogenase and nitrate reductase, are each associated with an anaerobic $b$-type cytochrome (Enoch \& Lester, 1974). Cytochrome $b$ (FDH) has been suggested to be associated with the $\gamma$-subunit $\left(M_{\mathrm{r}} 20000\right)$ of FDH-PMS by analogy with cytochrome $b(\mathrm{NR})$, which constitutes the $\gamma$-subunit of nitrate reductase. These cytochromes show a single $\alpha$-absorption peak at $559 \mathrm{~nm}$ at $25^{\circ} \mathrm{C}$. Moreover, cytochrome $b(\mathrm{NR})$ has been resolved into two distinct components with midpoint oxidationreduction potentials of $+20 \mathrm{mV}$ and $+120 \mathrm{mV}$ whereas cytochrome $b$ (FDH) titrates with a redox potential of about $-110 \mathrm{mV}$ (Hackett \& Bragg, 1983a, b). A clear distinction between the two specific cytochromes $b$ can be achieved on the basis of their differential response to certain electron donors. Ascorbate reduces only cytochrome $b$ (NR) whereas formate reduces both cytochrome $b$ (FDH) and cytochrome $b$ (NR) by the sequential transfer of electrons (RuizHerrera \& DeMoss, 1969). fdn mutants of Salmonella typhimurium specifically defective in the formation of FDH-PMS activity exhibited strong similarities with the fdhD mutants described here (Barrett \& Riggs, 1982). Their map position has been assigned to an equivalent site on the $S$. typhimurium chromosome, close to the rha locus, and all $f d n$ mutants produce an FDH-PMS protein comparable to that of the wild-type. However, spectral analysis revealed that they are defective in the anaerobic cytochrome $b_{559}$ associated with FDH-PMS. In order to compare these mutants with our own mutants, we examined their cytochrome $b$ composition by the sequential addition of ascorbate, formate and dithionite (the last causing the complete reduction of the cytochrome $b$ present) to cell preparations from the wild-type D54, the fdhD mutant FD17 and the fdhE mutant FD16 grown anaerobically with nitrate (Fig. 3). In strain D54, ascorbate reduced about $47 \%$ of the total cytochrome $b$ and the addition of formate resulted in a comparable increment of reduction. Dithionite led to a further $6 \%$ reduction, which could be attributable to the presence of cytochromes $b$ characteristic of aerobic respiratory pathways 

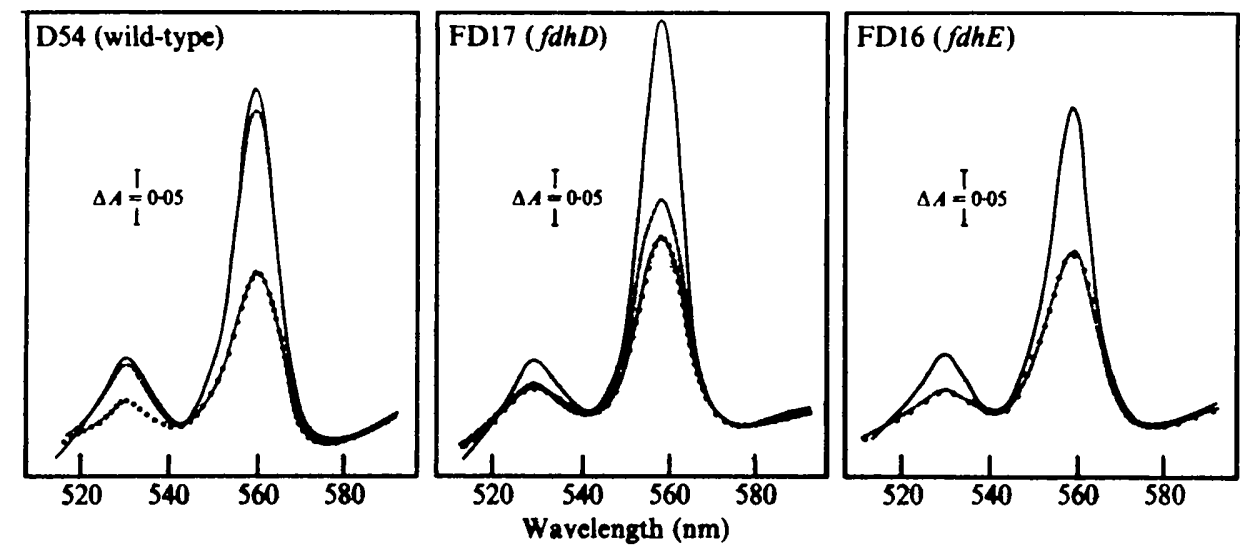

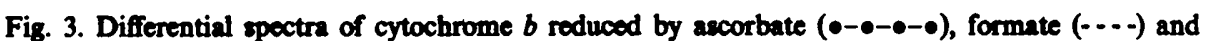
dithionite (-). Bacteria were grown annerobically in L-broth medium containing $1 \%$ potassium nitrate, wached and suspended in $50 \mathrm{~min}-\mathrm{Tris} / \mathrm{HCl}$ (pH 7.6) phus 1 mu-benzamidine, then frozen and thawed three times. Abeorption epectra were reconded at room temperature with a double-beam spectrophotometer (Denis \& Richaud, 1982). A $2.5 \mathrm{ml}$ sample of each cell suspension (about $16 \mathrm{~ms}$ protein $\mathrm{ml}^{-1}$ ) was introduced into one cuvette. The sumple was first oxidized by addition of $10 \mathrm{mu}$ potascium ferricyanide, and sequentially reduced by addition of 20 mu-ascorbate, 20 mu-formate and a few grains of dithionite. The height of the $\alpha$-peak of cytochrome $b$ was measured above the base line at $580 \mathrm{~nm}$ : it allowed the determination of the percentage of reduced cytochrome $b$.

(Hackett \& Brags, 1983a). In mutant FD17 $(f d h D)$, ascorbate also reduced about $46 \%$ of the cytochrome $b$ and the addition of formate promoted a further reduction of only $10 \%$. However, the total amount of cytochrome $b$ reduced by dithionite was of the same order of magnitude as that of the wild-type. Mutant FD16 ( $d h$ E) differed from both the wild-type and the $f d h D$ mutant in that its cytochrome content showed no reduction by formate, although normal levels of reduction by ascorbate and dithionite wore attained.

These results suggest that the cytochrome $b_{559}$ (FDH) is present in normal amounts in the $f d h D$ and $f d h E$ mutants of $E$. coli, but that it has lost in part $(f d h D)$ or totally ( $f d h E)$ its ability to be reduced by formate. These observations are also consistent with the hypothesis that the mutants produce an altered FDH-PMS apoprotein which is impaired in the transfer of electrons to cytochrome $b$ (FDH).

\section{DIsCUSSION}

We have described ten mutants of $E$. coli which specifically lack FDH-PMS activity, but which still produce functional nitrate reductase and formate hydrogenlyase activities. Although genetic analysis suggested that all the relevant mutations reside at the same site near the rha $D$ gene, these mutants have been clearly divided into two classes, $f d h D$ and $f d h E$, on the basis of their ability to reduce benzyl viologen with formate using an in situ dye overiay test on Petri dishes. $f d h D$ mutants appeared phenotypically FDH-BV- while $f d h E$ mutants were FDH-BV ${ }^{+}$, but all of them possessed a normal level of FDH-BV activity. It soems unlikely that this discrepancy could be attributed to difficulty in the access of benzyl viologen to its reaction site in vivo with FDH-BV, since (i) the non-permeant oxidized species of benzyl viologen is reduced by FDH-BV on the periplasmic side of the cytoplasmic membrane (Jones \& Garland, 1977), and (ii) when FDH-BV activity is assayed directly in intact $f d h D$ or $f d h E$ cells, this difference is no longer detectable. As the same phenomenon is also seen with formate hydrogenlyase activity, depending upon its investigation by gas production in Durham tubes or its measurement in whole cells by the Warburg method, we speculate that aggregation of colonies on agar or sedimentation at the bottom of Durham tubes could lead to the secondary loss of FDH-BV activity in the $f d h D$ mutants. In both cases, ageing of cells would result in this effect. 
Analysis of merodiploid $f d h D / f d h E$ strains, in which FDH-PMS activity is similar to the wildtype level, clearly supports the conclusion that both types of mutations are complementary to one another. In addition, immunological characterization with our antiserum raised against purified FDH-PMS indicated that, unlike the $f d h E$ mutants, the $f d h D$ mutants produced normal amounts of inactive membrane-bound FDH-PMS enzyme.

Several properties suggest that our mutants are different from the six $f d n$ mutants described in the equivalent region of the Salmonella typhimurium map (Barrett \& Riggs, 1982). Although they express a similar FDH-PMS- phenotype, the $f d n A, B, C$ mutants are distributed into at least three unlinked genetic sites between markers $g \ln A$ and $g l p K$. Moreover, all $f d n$ mutants synthesize an FDH-PMS protein similar to the wild-type protein. In this respect, only our $f d h D$ mutants would be likely to resemble $S$. typhimurium $f d n$ mutants. $f d h E$ mutants, which totally fail to make an FDH-PMS polypeptide, comprise a new class of mutants. Additional striking evidence allows us to separate the mutants isolated in $E$. coli and $S$. typhimurium. Spectral analysis of the cytochrome content of $f d h D$ and $f d h E$ mutants reveals the existence of both cytochromes $b_{559}$ (NR) and $b_{559}(\mathrm{FDH})$ in equal amounts to those found in the wild-type. In contrast, Barrett \& Riggs (1982) reported that all $f d n$ mutants of $S$. typhimurium had lost significant amounts or all cytochrome $b_{559}(\mathrm{FDH})$ and that they overproduced cytochrome $b_{559}$ (NR). They drew the conclusion that $f d n$ genes are possibly involved in the synthesis of a functional cytochrome $b_{559}(\mathrm{FDH})$. Formate still reduces, although with a weaker effect, cytochrome $b_{559}$ (FDH) in $f d h D$ mutants, but it has no effect in $f d h E$ mutants, which are unable to produce an FDH-PMS protein. Thus, we tentatively propose the hypothesis that $f d h D$ and fdhE genes might participate in the synthesis or the assembly of FDH-PMS apoprotein which consists of the three subunits $\alpha, \beta$ and $\gamma$. $f d h D$ mutants would synthesize normal amounts of a modified FDH-PMS which fails to transfer electrons from formate to cytochrome $b_{559}(\mathrm{FDH})$, due to limited access or to difficulty in the attachment of cytochrome $b$ to FDH-PMS. One could also imagine that the structure of FDH-PMS protein has been mutated in such a way that it has lost its affinity for formate and thus cannot liberate carbon dioxide and electrons. In fact, $f d h D$ mutants might be defective in the structural gene of either the $\alpha$ or the $\beta$ subunit, provided that the finding that cytochrome $b_{559}(\mathrm{FDH})$ is not essential for FDH-PMS activity assayed with PMS as electron acceptor still holds (Ruiz-Herrera \& DeMoss, 1969). On the other hand, the behaviour of the $f d h E$ mutants, totally devoid of FDH-PMS protein, is reminiscent of the loss of a positive regulator that would activate the anaerobic transcription of genes involved in the synthesis of FDH-PMS. Alternatively, the FdhE- phenotype might result from the absence of a structural component required for the integrity of the enzyme, which would thus become degraded when it was lacking. By comparison, Barrett \& Riggs (1982) did not detect any reduction of cytochrome $b_{559}$ (FDH) by formate in an $f d h A$ mutant of $S$. typhimurium deficient in both FDH activities and in FDH-PMS protein: spectral analysis of the cytochrome content was identical to that of our $f d h E$ mutant and its typical pattern was attributed to a faulty FDH-PMS enzyme itself.

Further genetic experiments, including molecular cloning and in vivo expression, are in progress to define the gene product-function relationship of $f d h D$ and $f d h E$.

\footnotetext{
We are indebted to $M$. Denis and P. Richaud for generous help with the cytochrome scans and to F. Stoeber for encouragement. We wish to thank J. Pellissier and S. Ottomani for preparing microbiological media, C. van Herrewege for assistance in the illustrations and G. C. Barr reading the manuscript.

This work was supported by grants from the Centre National de la Recherche Scientifique.
}

\section{REFERENCES}

Azoulay, E. \& MARTY, B. (1970). Etude du système multienzymatique hydrogène lyase chez Escherichia coli $\mathrm{K} 12$ et ses mutants chlorate-résistants. European Journal of Biochemistry 13, 168-173.
BARRETT, E. L. \& RIGGS, D. L. (1982). Salmonella typhimurium mutants defective in the formate dehydrogenase linked to nitrate reductase. Journal of Bacteriology 149, 554-560. 
Barrett, E. L., Jackson, C. E., Fukumoto, H. T. \& Chang, G. W. (1979). Formate dehydrogenase mutants of Salmonella typhimurium: a new medium for their isolation and new mutant classes. Molecular and General Genetics 177, $\overline{95}-101$.

Chippaux, M., Pascal, M. C. \& Casse, F. (1977). Formate hydrogenlyase system in Salmonella typhimurium LT2. European Journal of Biochemistry 72, 149-155.

Cox, J. C., Edwards, E. S. \& DeMoss, J. A. (1981). Resolution of distinct selenium containing formate dehydrogenases from Escherichia coli. Journal of Bacteriology 145, 1317-1324.

Denis, M. \& Richaud, P. (1982). Dynamics of COrecombination to fully reduced cytochrome $c$ oxidase in plant mitochondria after low to flash photolysis. Biochemical Journal 206, 379-385.

ENOCH, H. G. \& LESTER, R. L. (1974). The role of a novel $b$-containing nitrate reductase and quinone in the in vitro reconstruction of formate-nitrate reductase activity of Escherichia coli. Biochemical and Biophysical Research Communications 61, 1234-1241.

ENOCH, H. G. \& Lester, R. L. (1975). Purification and properties of formate dehydrogenase and nitrate reductase from Escherichia coli. Journal of Biological Chemistry 250, 6693-6705.

Giordano, G., GrahaM, A., Boxer, D. H. \& Azoulay, E. (1978). Characterization of the membrane-bound nitrate reductase activity of aerobically grown chlorate-sensitive mutants of Escherichia coli K12. FEBS Letters 95, 290-294.

Giordano, G., Haddock, B. A. \& Boxer, D. H. (1980). Molybdenum-limited growth achieved either phenotypically or genotypically and its effect on the synthesis of formate dehydrogenase and nitrate reductase by Escherichia coli K12. FEMS Microbiology Letters 8, 229-235.

Grordano, G., Medani, C. L., Mandrand-BertheLOT, M. A. \& BOXER, D. H. (1983). Formate dehydrogenases from Escherichia coli. FEMS Microbiology Letters 17, 171-177.

GLASER, J. H. \& DEMoss, J. A. (1972). Comparison of nitrate reductase mutants of Escherichia coli selected by alternative procedures. Molecular and General Genetics 116, 1-10.

Graham, A., Jenkins, H. E., Smith, N. H., MaNDRAND-Berthelot, M. A., HADDOCK, B. A. \& BOXER, D. H. (1980). Synthesis of formate dehydrogenase and nitrate reductase proteins in various $f d h$ and chl mutants of Escherichia coli. FEMS Microbiology Letters 7, 145-151.

HACKeTt, N. R. \& BraGg, P. D. (1983a). Membrane cytochromes of Escherichia coli grown aerobically and anaerobically with nitrate. Journal of Bacteriology 154, 708-718.

HACKETT, N. R. \& BRAGG, P. D. (1983b). Membrane cytochromes of Escherichia coli chl mutants. Journal of Bacteriolology 154, 719-727.

HADDOCK, B. A. \& Jones, C. W. (1977). Bacterial respiration. Bacteriological Reviews 41, 47-99.

HADDOCK, B. A. \& MandRand-Berthelot, M. A. (1982). Escherichia coli formate-to-nitrate respiratory chain: genetic analysis. Biochemical Society Transactions 10, 478-480.

JONES, R. W. \& GARLAND, P. B. (1977). Sites and specificity of the reaction of bipyridylium compounds with anaerobic respiratory enzymes of Escherichia coli. Biochemical Journal 164, 199-211.

LESTBR, R. L. \& DEMoss, J. A. (1971). Effects of molybdenum and selenite on formate and nitrate metabolism in Escherichia coli. Journal of Bacteriology 105, 1006-1014.

Low, K. B. (1972). Escherichia coli K-12 F-prime factors, old and new. Bacteriological Reviews 36, 587607.

MANDRAND-Berthelot, M. A., WeE, M. Y. K. \& HADDOCK, B. A. (1978). An improved method for the identification and characterization of mutants of Escherichia coli deficient in formate dehydrogenase activity. FEMS Microbiology Letters 4, 37-40.

MILLER, J. H. (1972). Experiments in Molecular Genetics. Cold Spring Harbor, NY: Cold Spring Harbor Laboratory.

Murgola, E. J. \& Yanofsxy, C. (1974). Structural interactions between amino acid residues at positions 22 and 211 in the tryptophan synthetase alpha chain of E. coli. Journal of Bacteriology 117, 444-448.

PeCK, H. D. \& Gest, H. (1957). Formic dehydrogenase and the hydrogenlyase enzyme complex in the coliaerogenes group. Journal of Bacteriology 73, 706-721.

POWER, J. (1967). The L-rhamnose genetic system in Escherichia coli K-12. Genetics 55, 557-568.

RuIz-HerrerA, J. \& DeMoss, J. A. (1969). Nitrate reductase complex of Escherichia coli K12: participation of specific formate dehydrogenase and cytochrome $b_{1}$ components in nitrate reduction. Joumal of Bacteriology 99, 720-729.

StewarT, V. \& MACGregor, C. H. (1982). Nitrate reductase in Escherichia coli K-12: involvement of chlC, chlE and chlG loci. Joumal of Bacteriology 151, 788-799.

WU, L. F. \& MANDRAND-Berthelot, M. A. (1986). Genetic and physiological characterization of new Escherichia coli mutants impaired in hydrogenase activity. Biochimie 68, 167-179. 